\title{
Malthus for kids: The impact of exploring Malthus' principle on elementary school students' understanding of evolution by natural selection
}

\author{
Xana Sá-Pinto ${ }^{1}$, Alexandre Pinto ${ }^{2}$, Joana Ribeiro ${ }^{2}$, Inês Sarmento ${ }^{2}$, Patrícia Pessoa ${ }^{1}$, \\ Leonor Rodrigues ${ }^{3}$, Lucía Vázquez-Ben ${ }^{4}$, Evangelia Mavrikaki ${ }^{5}$, and Joaquim Bernardino \\ Lopes $^{6}$ \\ ${ }^{1}$ University of Aveiro Research Centre Didactics and Technology in Education of Trainers \\ ${ }^{2}$ Polytechnic Institute of Porto School of Education \\ ${ }^{3}$ Centre for Ecology Evolution and Environmental Changes \\ ${ }^{4}$ Faculty of Educational Studies, Universidade da Coruña \\ ${ }^{5}$ Faculty of Primary Education, National \& Kapodistrian University of Athens \\ ${ }^{6}$ Universidade de Trás-os-Montes e Alto Douro
}

February 27, 2021

\begin{abstract}
While several researchers have suggested that evolution should be explored from the initial years of schooling, little information is available on effective resources to enhance elementary school students' level of understanding of evolution by natural selection (LUENS). For the present study, we designed, implemented and evaluated an educational activity planned for fourth graders to explore concepts and conceptual fields that were historically important for the discovery of natural selection. Observation field notes and students' productions were used to analyse how the students explored the proposed activity. Additionally, an evaluation framework consisting of a test, the evaluation criteria and the scoring process was applied in two fourth-grade classes to estimate elementary school students' LUENS before and after engaging in the activity. Our results suggest that our activity allowed students to effectively link all of the key concepts in the classroom and produced a significant increase in their LUENS. These results indicate that our activity had a positive impact on students' understanding of natural selection. They also reveal that additional activities and minor fine-tuning of the present activity are required to further support students' learning about the concept of differential reproduction. We also observed a low level of teleological predictions for both pre- and post-tests.
\end{abstract}

\section{Hosted file}

malthus_submission.pdf available at https://authorea.com/users/398447/articles/511069malthus-for-kids-the-impact-of-exploring-malthus-principle-on-elementary-schoolstudents-understanding-of-evolution-by-natural-selection 


\begin{tabular}{|c|c|c|c|}
\hline HIGH LEVEL CON & EMBODIMENTS & MEDIATING PROCESSES & MES \\
\hline $\begin{array}{l}\text { Learning about Malthus } \\
\text { principle through a } \\
\text { transdisciplinary problem- } \\
\text { based learning approach } \\
\text { that includes intraspecific } \\
\text { diversity in heritable } \\
\text { characters may facilitate } \\
\text { linking relevant key } \\
\text { concepts required to } \\
\text { understand natural } \\
\text { selection, fostering } \\
\text { elementary school students' }\end{array}$ & 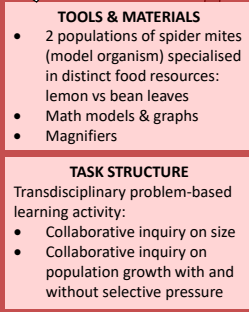 & 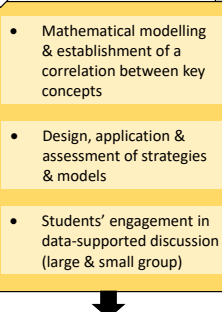 & $\begin{array}{l}\text { Produce natural selection- } \\
\text { based explanations } \\
\text { - Grasp key concepts for } \\
\text { natural selection } \\
\text { (selective pressure, } \\
\text { differential survival, } \\
\text { differential reproduction, } \\
\text { differential fitness, } \\
\text { frequency changes in the } \\
\text { poulation) and natural } \\
\text { selection itself }\end{array}$ \\
\hline \begin{tabular}{l}
\multicolumn{1}{c}{ BASED ON: } \\
- History of Science proved \\
helpful \\
- Malthus principle= key for \\
Darwin \& Wallace \\
- PBL proved effective for \\
significant Science learning
\end{tabular} & 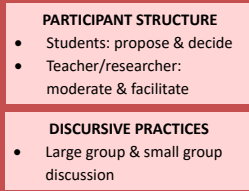 & $\begin{array}{l}\text { TO BE CAPTURED BY: } \\
\text { Participant observation } \\
\text { Participant artifacts }\end{array}$ & $\begin{array}{l}\text { - Develop math skills: } \\
\text { estimation \& graphical } \\
\text { representation }\end{array}$ \\
\hline
\end{tabular}
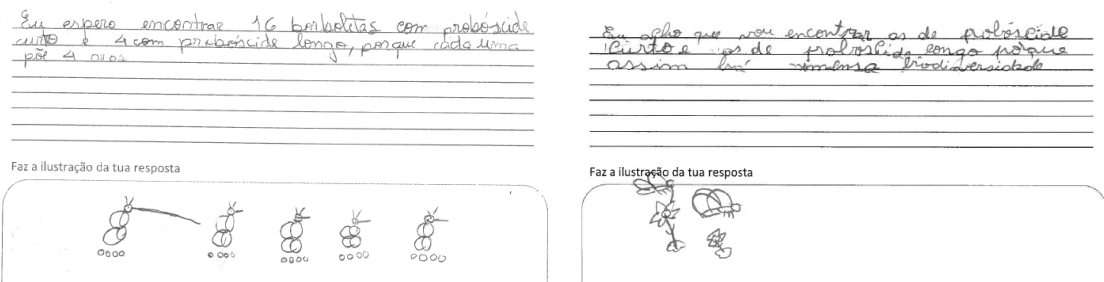

a

b
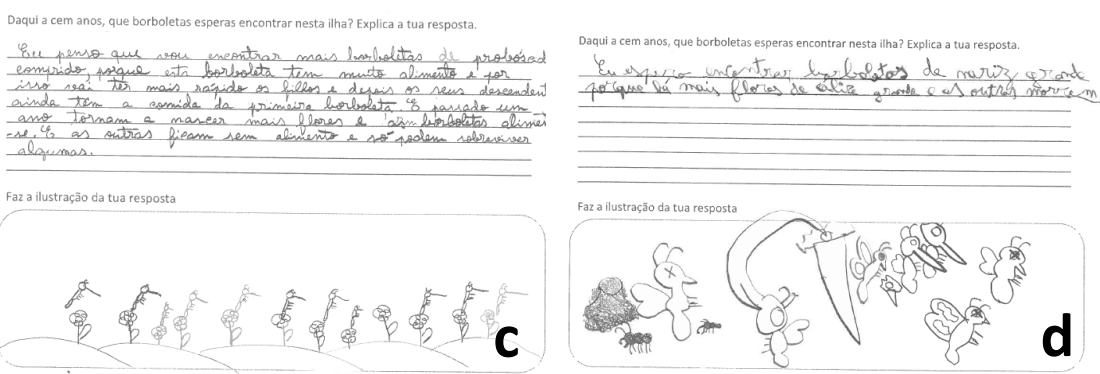
a)

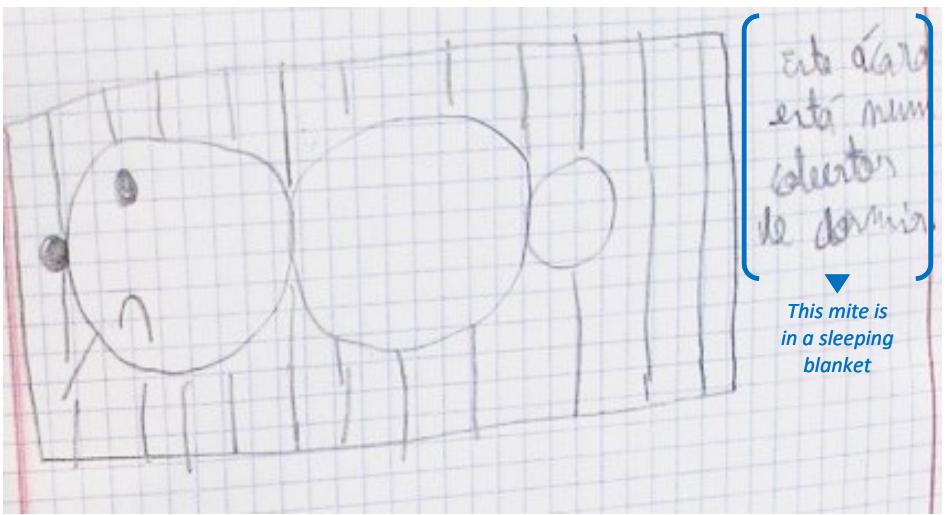

b)
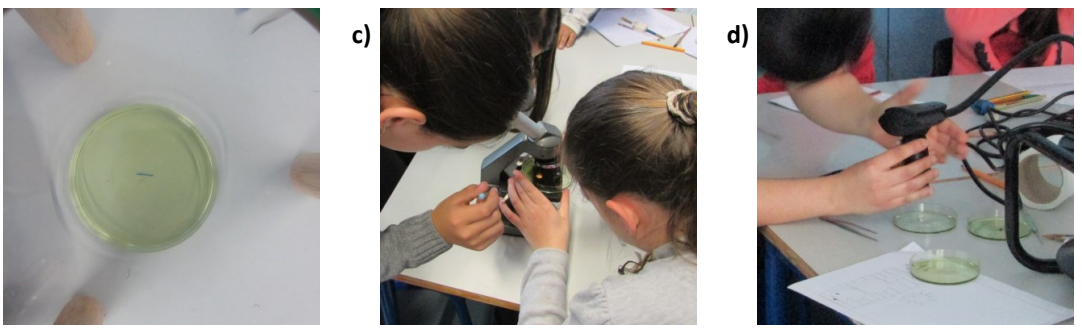

e)

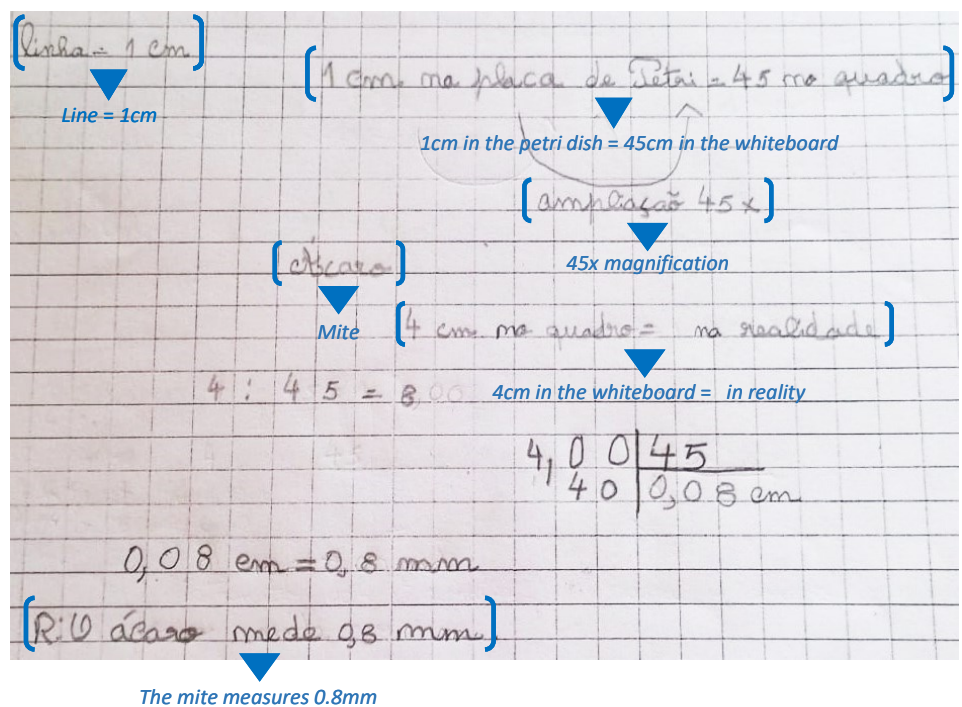


a)

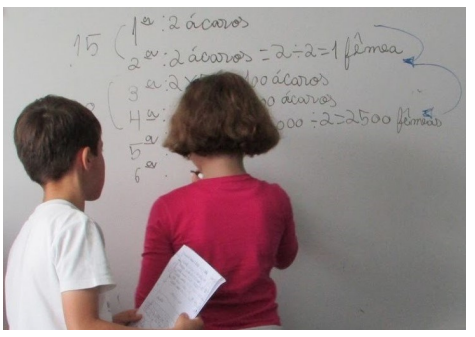

b)

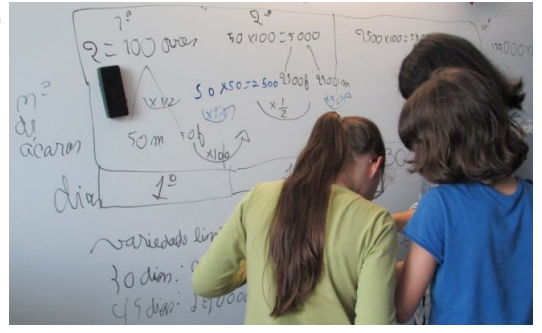

c)

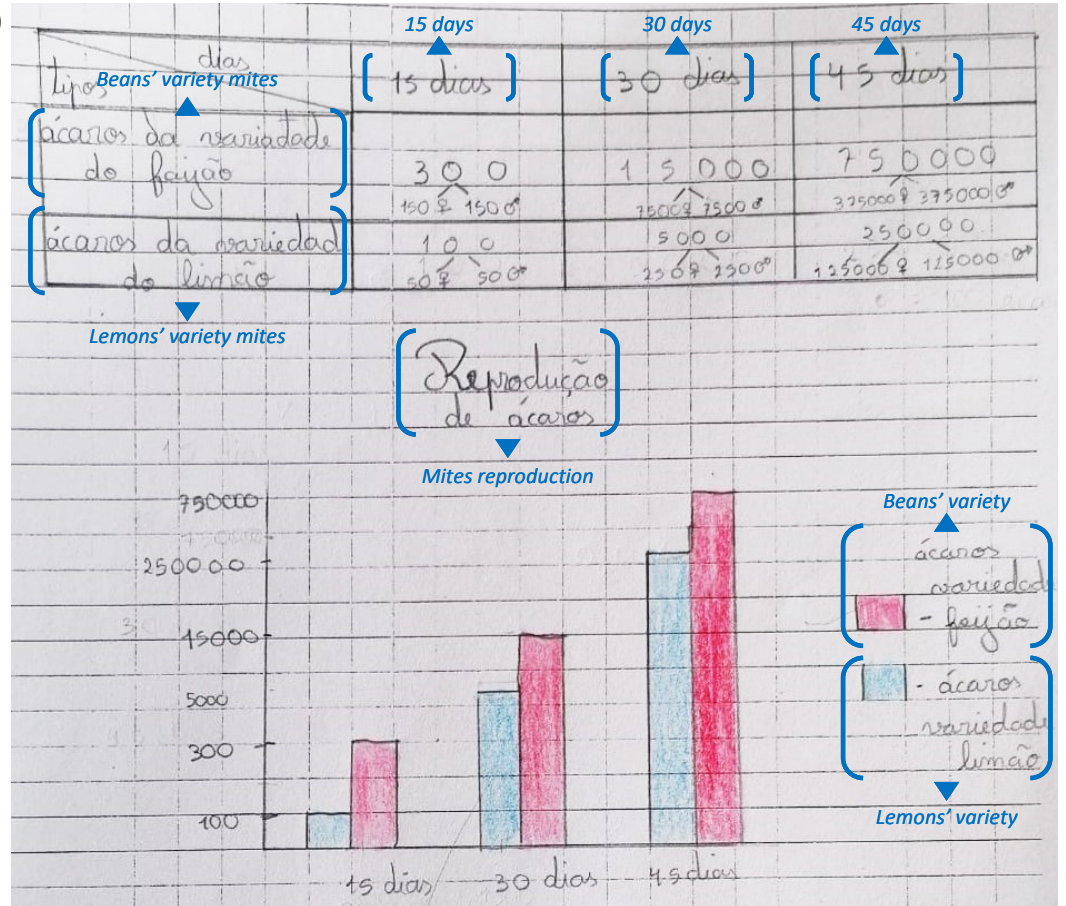


a)

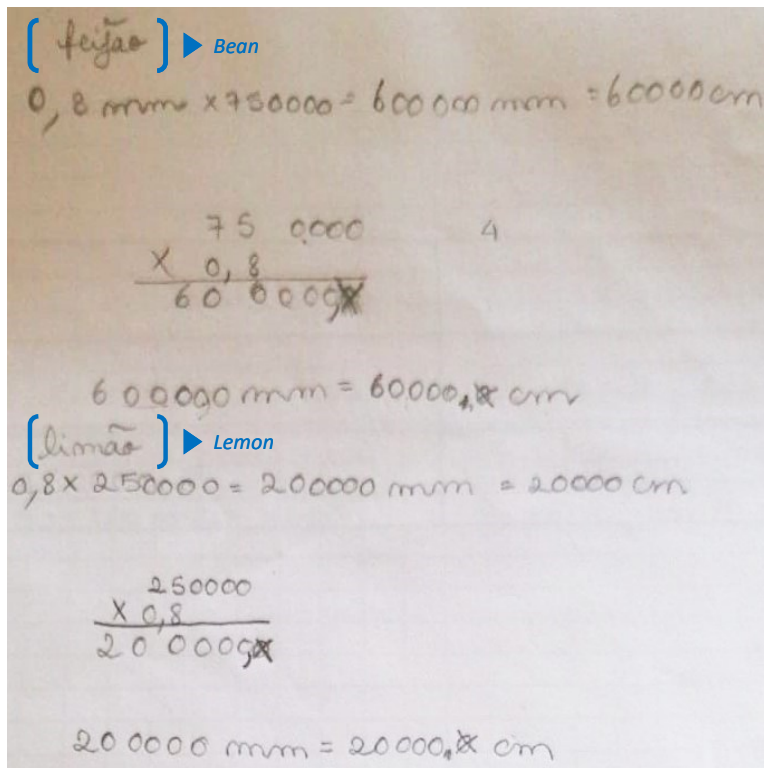

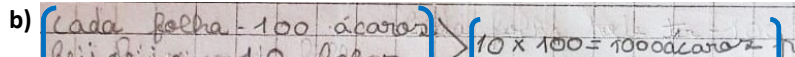

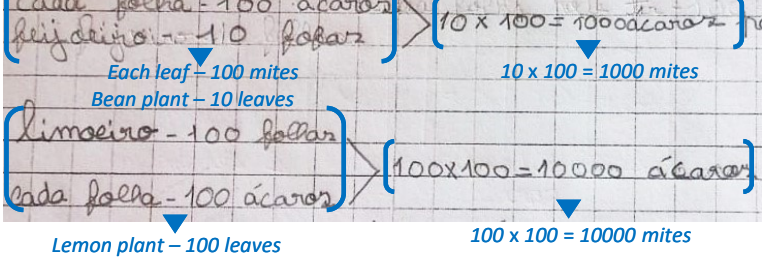
Each leaf -100 mites

c)

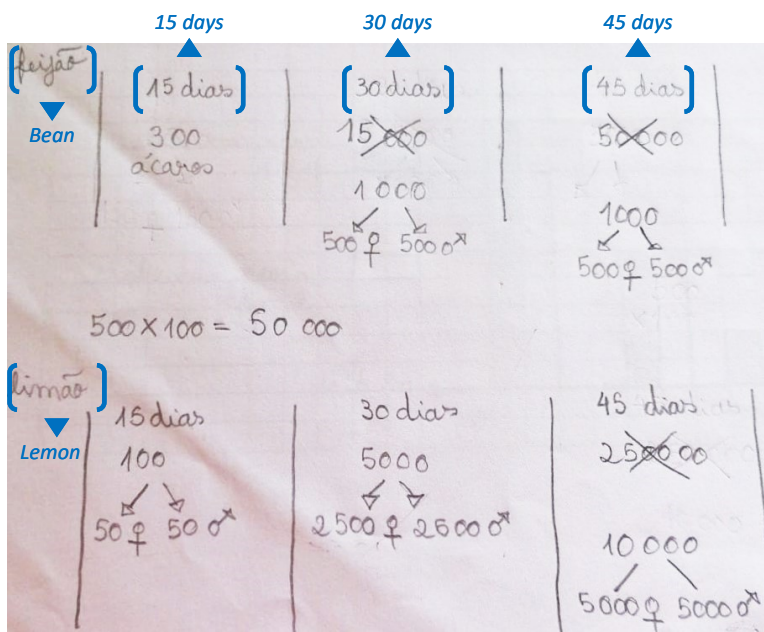



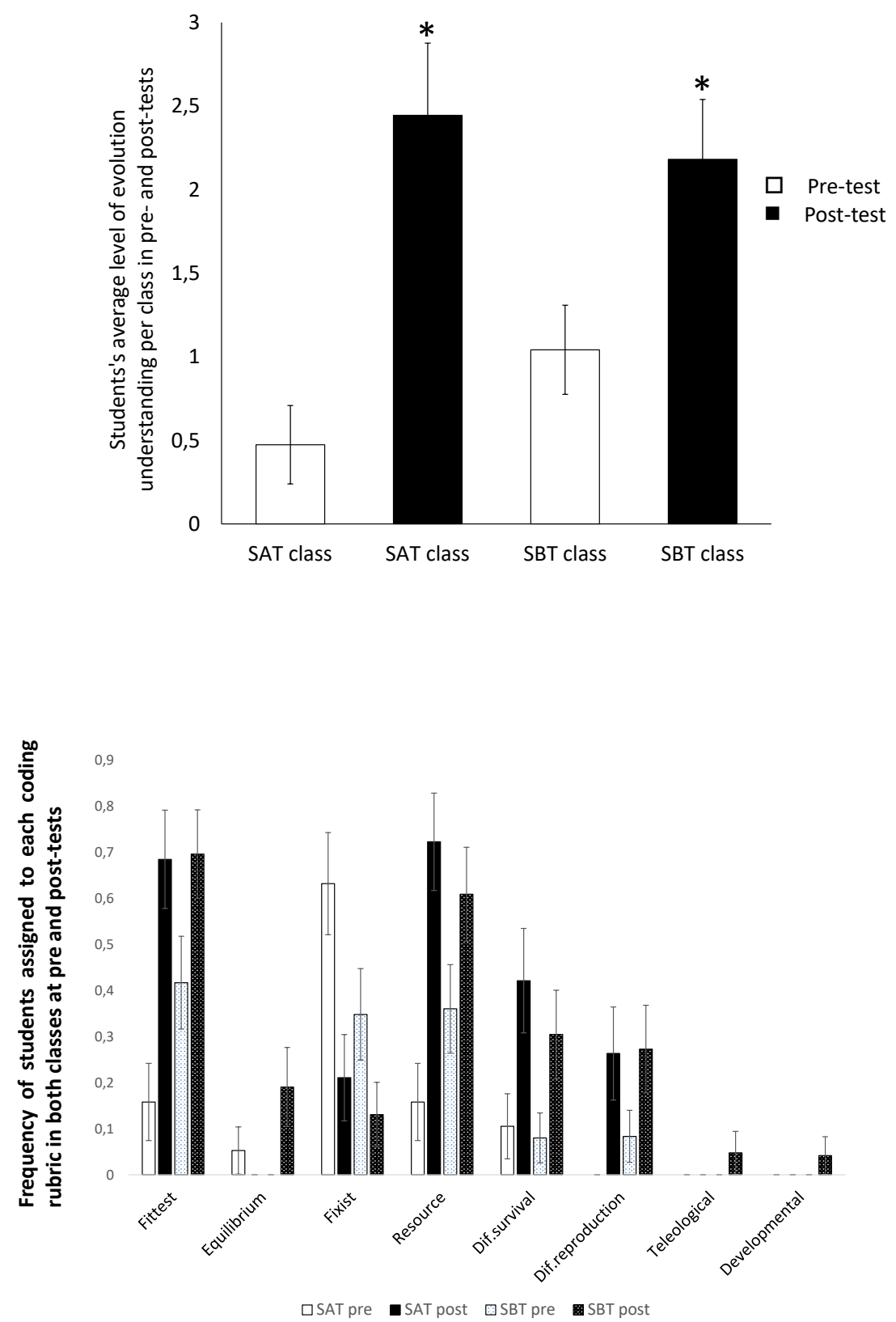